these two patients the difference between the treated and the control group would have been correspondingly greater.

The clinical condition of the survivors was fairly similar in the two groups; significantly more control patients had no angina pectoris, but more control patients needed digitalis and diuretics. The same proportion of the survivors returned to work. It should be remembered, however, that 11 patients in the control group and two treated patients died before the end of the observation period.

The mean Thrombotest value achieved was $15.9 \%$, which compares favourably with previous studies from Scandinavia (Bjerkelund, 1957 ; Borchgrevink, 1960, 1962 ; Harvald et al., 1962 ; Aspenström and Bengtsen, 1964 ; Sørensen et al., 1968), but which is higher than that recently reported from Holland (Loeliger et al., 1967). Half the tests were between 5 and $14 \%$ Thrombotest, which is satisfactory. The bleeding complications were all trivial, and no patient had to be admitted to hospital or to stop treatment because of them.

Our results are in agreement with those of Claussen et al. (1961), Aspenström and Bengtsen (1964) and Sørensen et al. (1968), but differ from those obtained by Bjerkelund (1957) and the M.R.C. (1959), who did not find any beneficial effect of long-term anticoagulant therapy in female patients. It is possible that differences in selection of patients may explain the difference in the results. Other statistically satisfactory studies on long-term anticoagulant therapy have included only men (Veterans Administration, 1965 ; Lovell et al., 1967) or have not given the morbidity or mortality separately for the two sexes (Harvald et al., 1962 ; Seaman et al., 1964), and hence cannot be compared with the present study.

An editorial in the British Medical fournal (1964), while advocating long-term anticoagulant therapy in younger men, concluded: "... there seems to be little justification for giving women long-term anticoagulant therapy." Nevertheless, there is no valid theoretical or practical reason for believing that the effect of long-term anticoagulant therapy is materially different in the two sexes. However, while in men the effect seems to be more pronounced below the ages of 55 to 60 years, in women our study shows that there is an effect on both the mortality and the reinfarction rate between the ages of 60 and 70. Our study does not answer the question whether younger women would also benefit from long-term anticoagulant therapy, though there is a suggestion of an effect on the reinfarction rate.

The present study cannot answer how long the therapy should last. The effect seems to be maximal during the first three months after discharge from hospital, but our results do not rule out that the effect lasts longer. From our study and from recently published accounts we think it is logical to adopt the same policy on instituting and maintaining long-term anticoagulant therapy in women as in men. By carefully crossanalysing all the data we had hoped to be able to correlate the positive effect of the treatment with certain features in the patient's history. We were, however, unable to find any subgroup of patients in whom the therapy was effective and other subgroups in whom it was ineffective. It may be argued, however, that with our method of selection we were already dealing with a subgroup of female patients with myocardial infarction.

Requests for reprints should be addressed to Chr. Barchgrevink, Deph VII, Ullevål Hospital, Oslo, Norway.

\section{REFERENCES}

Aspenström, G., and Bengtsen, K., (1964). Acta med. scand., 176, 563. Bjerkelund, Chr J. (1957). Acta med. scand., 158, Suppl. No. 330. Borchgrevink, Chr. F. (1960). Acta med. scand., 168, Suppl. No. 359.

Borchgrevink, Chr. F. (1962). Lancet, 1, 449.

Brit. med. \%., 1964, 2, 831.

Claussen, J., et al.' (1961). Ugeskr. Lag., 123, 987.

Harvald, B., Hilden, T., and Lund, E. (1962). Lancet, 2, 626

Sørensen, Ö. H., Friis, Th. Jørgensen, A. W., Jørgensen, M. B., and Nissen, N. I. (1968). Ü geskr. Lag., 130, 318.

Loeliger, E. A., et al. (1967). Acta med. scand., 182, 549.

Lovell, R. R. H., Denborough, M. A., Nestel, P. J., and Goble, A. J. (1967). Med. 7. Aust., 2, 97.

Medical Research Council (1959). Brit. med. F., 1, 803.

Seaman, A. J., Griswold, H E., Reaume, R. B., and Ritzman, L. W (1964). Y. Amer. med. Ass., 189, 183.

Veterans Administration (1965). '. Amer. med. Ass., 193, 929.

\title{
Effects of Asbestos in Dockyard Workers
}

\author{
GEOFFREY SHEERS,* M.A., M.D.; ANN R. TEMPLETON, $\dagger$ M.B., CH.B.
}

[With Special Plate facing Page 574]

Brit. med. F., 1968, 3, 574-579

\begin{abstract}
ummary : The prevalence of pleural and pulmonary $\checkmark$ abnormalities attributed to asbestos among 15,000 workers in a naval dockyard has been studied by means of a one-in-ten sample. Ninety-four per cent. of the men in the sample were examined. Of these, $3 \%$ had experienced continuous occupational exposure to asbestos and half of the remainder (representing approximately 6,800 men) had been exposed intermittently. The prevalence of pleural fibrosis ranged from $28 \%$ in continuously exposed workers to $1.9 \%$ in those with least exposure.

Most cases of pulmonary fibrosis occurred in laggers and sprayers who had been continuously exposed for between 15 and 20 years. Pulmonary fibrosis was also seen in a variety of intermittently exposed trades, and had been preceded by extensive pleural thickening in some cases. Ten cases of pleural mesothelioma have occurred in the last three years and a large number of men appear to be potentially at risk.
\end{abstract}

- Consultant Chest Physician, Plymouth General Hospital.

\section{Introduction}

From 1958 onwards cases of pleural and pulmonary fibrosis have been discovered in men working at the Royal Dockyard at Devonport, partly in the course of routine examinations in the dockyard and partly among patients with symptoms referred to the local chest clinic. Further investigation has confirmed an association between these conditions and exposure to asbestos, and by 1964, when the first case of pleural mesothelioma was identified, it was evident that a serious increase in the hazards arising from the use of this material had developed.

In 1966 it became practicable to carry out a large-scale survey with a radiographic technique of adequate quality, and the opportunity was taken to incorporate a one-in-ten sample of workers. This paper is concerned mainly with the results of the survey, and in particular with the prevalence of abnormalities attributed to asbestos and their relation to. exposure.

† Medical Director, Mass Radiography Centre, Plymouth. 


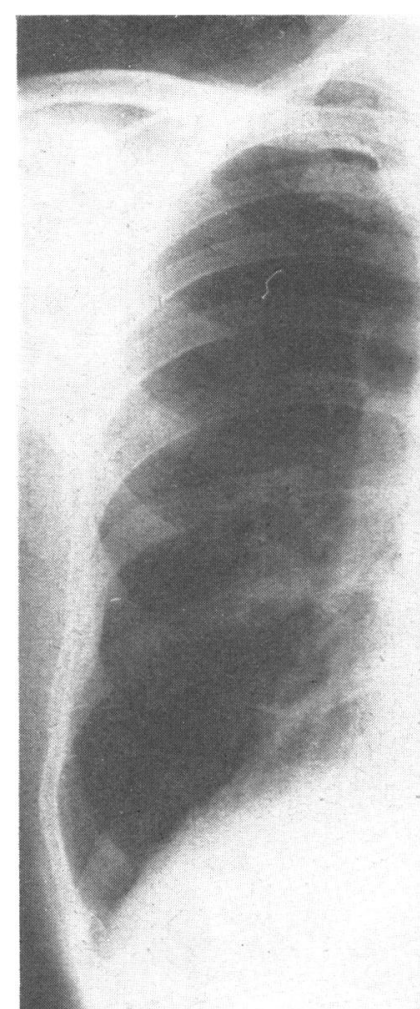

FIG. 1.-Limited pleural plaque in a boilermaker aged 63,43 years after first exposure.

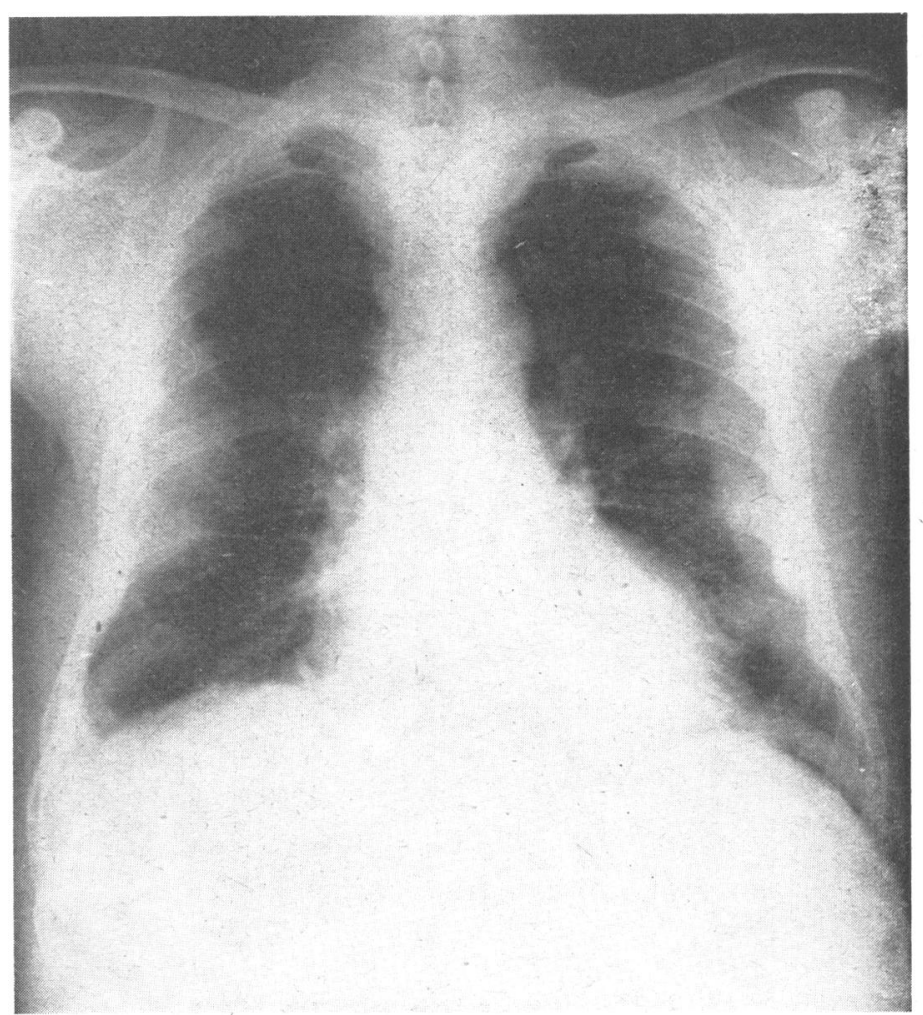

FIG. 2.-Extensive parietal pleural thickening in a labourer aged 60,30 years after first exposure.

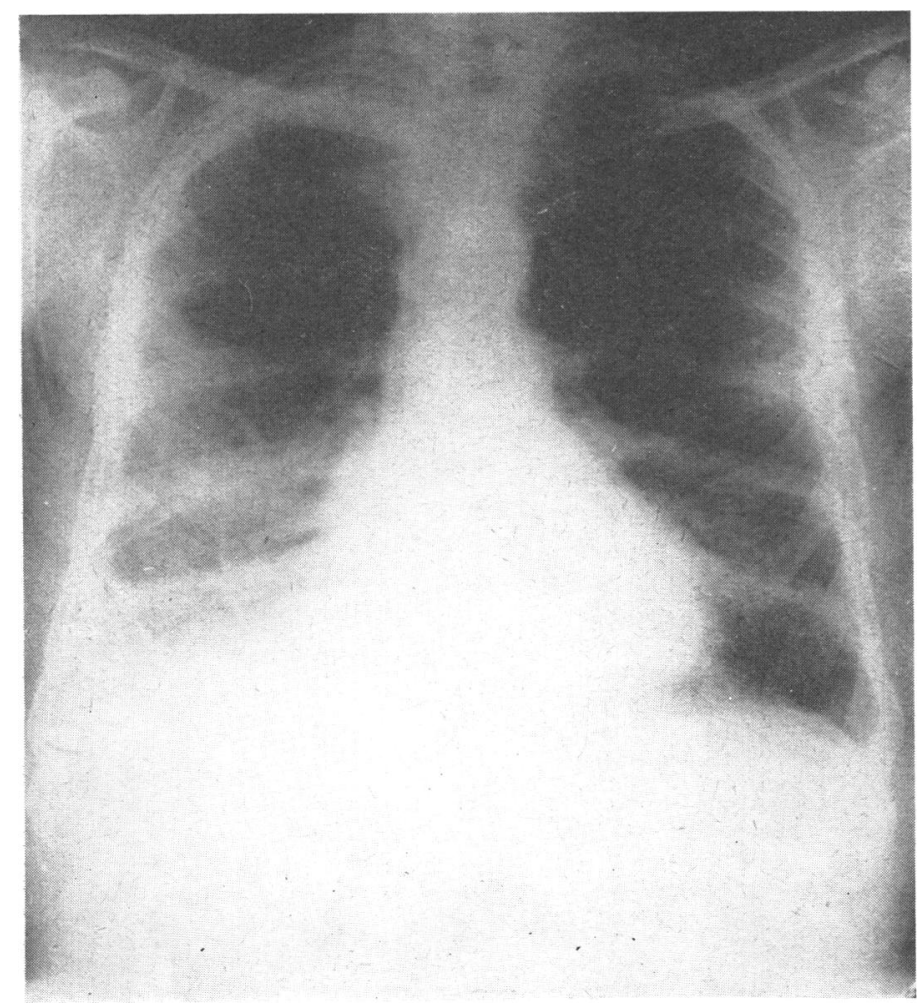

Fig. 3.-Diffuse lower zone pleural fibrosis in an electrical fitter aged 68 , 48 years after first exposure.

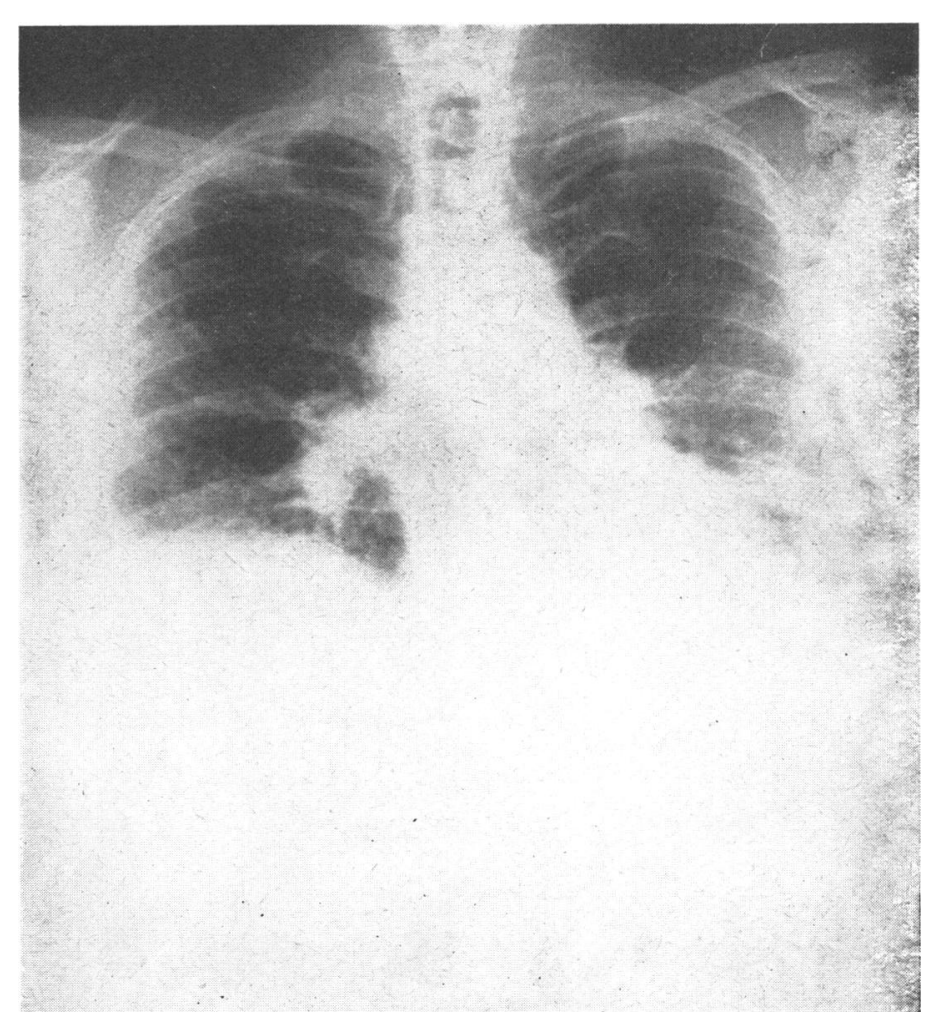

FIG. 4.-Pulmonary fibrosis in a labourer aged 63,30 years after first exposure. 


\section{Working Environment}

The conditions of work in Devonport Dockyard have been more fully described elsewhere (Harries, 1968). They can be summarized by comparison with methods of work in commercial shipyards and by reference to changes in practice during the postwar years leading to the large increase in the amount of asbestos handled.

A naval dockyard is concerned largely with refitting and modernization, and only to a lesser extent with new construction. A major refit is likely to require the removal of a large proportion of all types of insulating material, and it is the stripping and removal of old lagging rather than new application which causes hazardous working conditions with very high dust counts. This work is done at the same time as many other jobs, and all these activities take place in small illventilated compartments. As a result workers in a variety of trades not directly concerned with the handling of asbestos are exposed to the same working conditions.

Changes in practice arose from the demand for better insulation to meet the need for improved environmental conditions in tropical waters, lessening of fire risks, closed ventilation and recirculation of air during simulated atomic warfare, and improved efficiency in propulsion machinery. These constructional demands developed in the later war years and continued into the early postwar period, resulting in a maximum level of exposure during refits between 1950 and 1963. All types of asbestos fibre were used. Significant examples are the use of pure amosite sections for high-temperature steam-pipe insulation and the use of crocidolite to cover very large areas below the flight decks of aircraft carriers.

It must be emphasized that these conditions no longer prevail, and that a drastic reorganization of working practice has been carried out in order to minimize the risks of using asbestos.

\section{Population Studied}

\section{Methods}

The Navy Department employs some 21,000 civilians in the Plymouth area. All activities connected with shipbuilding and refitting are confined to the main dockyard, comprising North and South Yards at Devonport. The number employed in the main dockyard is 15,765 , and the relevant subdivisions of the occupational structure are shown in Table $I$.

TABLE I.-Occupational Structure of Main Dockyard

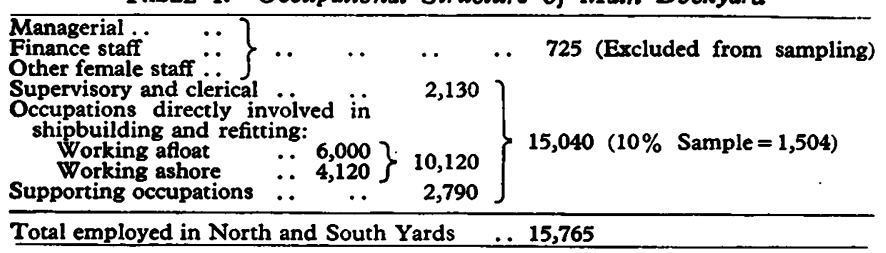

Men on the weekly pay roll of the North and South Yards are recorded numerically on a computer tape, and advantage was taken of this procedure to obtain a $10 \%$ sample. This method excluded managerial and finance staff, and for the sake of simplicity 15 other female workers were also excluded.

The remaining 15,040 men form the subject of the survey. The number working afloat at any one time is estimated to be 6,000 , but on account of the constant interchange between work afloat and work ashore this can be only an approximation. Most of the exposure to asbestos dust occurs within this group, but the number exposed varies considerably from day to day. The average is in the neighbourhood of 2,000 .

The $10 \%$ sample, consisting of 1,504 men, was used for the study of prevalence and exposure. Chest radiography was also offered to all other workers in the dockyard, and an additional
7,687 men were examined in this way. A more detailed study of 420 men, including all those known to have been continuously exposed, is being carried out concurrently as a separate investigation.

\section{Response}

Efforts were made to trace every man in the $10 \%$ sample. In addition to the small number who were too ill to attend or who died near the time of the survey there were 25 who left the district without trace and a final residue of 59 men who refused to co-operate. The remaining 1,414 men were examined, indicating a response of $94 \%$ (Table II).

TABLE II.-Response to Examination

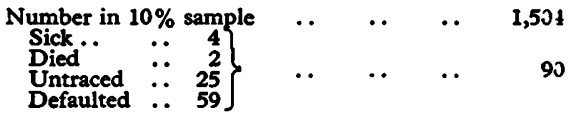

Number examined $1,414=94 \%$

\section{Examination}

Men in the $10 \%$ sample recorded their industrial histories on a standard form, and the record was checked by a trained assistant at the time of radiographic examination.

The initial radiograph in the majority of cases was the 100 by $100 \mathrm{~mm}$. photofluorograph produced by the Odelca camera (which incorporates a stationary grid), coupled to a $200 \mathrm{~mA}$ $\boldsymbol{x}$-ray generator and phototimer.

The films were read by both of us independently, and in any case where an abnormality was suspected by either reader the subject was recalled for confirmatory radiographic examination and for verification of the industrial history. Clinical examination was carried out in all cases in which an abnormality had been attributed to exposure to asbestos, and the pulmonary function was examined in all those in which there was any suspicion of involvement of the lung parenchyma.

\section{Analysis of Exposure}

The measurement of exposure in terms of dust concentrations and time exposed was impracticable on account of the wide variations in working conditions. In the small group of men whose work involved continuous handling of asbestos the number of years spent in the job provided a fair basis for comparison, but for the great majority of men in the dockyard these conditions did not apply. Even after taking a most detailed industrial history it was often impossible to make a reasonable estimate of the proportion of working time that had been spent under hazardous conditions. The analysis was therefore based on the trade in which each man had worked

TABLE III.-Exposure Groups

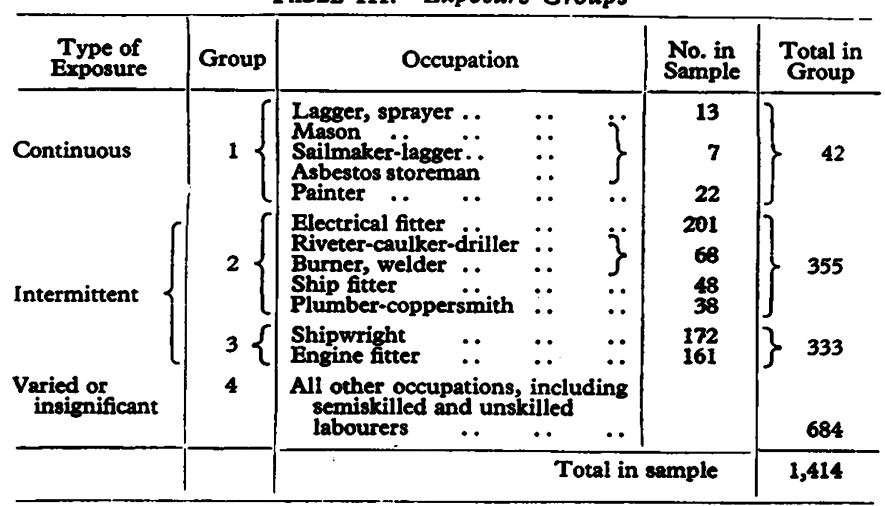


for the greater part of his time in the dockyard. Two measurements were made: firstly, the number of years spent in the trade, and, secondly, the number of years since first employment in the trade. Trades have been grouped in order to provide numbers of sufficient size for analysis (Table III).

The first group consists of occupations which involved continuous exposure. Of these, the laggers and sprayers were the most heavily exposed, but there were also a small number of men who used asbestos cement and asbestos cloth or who handled the material in stores. Painters have been included in this group, since their work is mainly below decks and regularly involves the cleaning of surfaces heavily contaminated by asbestos (exterior painting is done by men in the semiskilled category).

The other principal trades concerned in ship refitting have been divided between the second and third groups. All these occupations involved intermittent exposure to asbestos, and it would be difficult for the casual observer to detect large differences in the degree of exposure between one trade and another. Of the three bigger trades, the electrical fitters appeared to be at risk for a somewhat larger proportion of working time than the shipwrights and engine fitters. By placing the two latter trades in a separate group it was hoped to gain an impression of the range of prevalence of abnormalities experienced by intermittently exposed men.

The fourth group comprises many occupations, of which the majority do not involve significant exposure, but it includes a large number of semiskilled and unskilled workers who are liable to frequent changes of job. Some of these men worked as assistants to tradesmen in the second and third groups. Others were employed in stripping and clearing up lagging, and were thus heavily exposed at times.

\section{Abnormalities Attributed to Asbestos}

\section{Radiographic Appearances}

The commonest finding was the limited plaque of pleural thickening. This is best seen on the lateral chest wall, as in this situation it is tangential to the $x$-ray beam. It is characteristically bilateral and does not involve the costophrenic angle (Fig. 1, Special Plate). Plaques may also be present on the diaphragmatic and mediastinal pleura but are difficult to observe unless of calcific density. Plaques on the anterior and posterior chest wall may become visible when of similar density. These may show the so-called holly-leaf outline, but can range from uniformly opaque, very dense shadows to faint groups of nodules which may be difficult to see but which probably represent an earlier stage in the process of focal deposition of calcium in the periphery of the plaque. This latter variety can be a cause of difficulty in interpreting the pulmonary pattern.

More extensive pleural thickening was also seen. In these cases the peripheral opacity overlaps the lung field to a varying extent. The inner outline of the opacity may be quite well defined when the main area of thickening is situated laterally (Fig. 2, Special Plate), but is frequently indistinct, becoming progressively more faint as it fades into the central area of the lung field. Involvement of the costophrenic angle and lower zone is not uncommon, and this extension of the pleural reaction has been observed within a period of three months (Fig. 3, Special Plate). It may be accompanied by a small effusion. Such cases may present in clinic practice, especially when associated with an acute episode of pleural pain, but others have developed insidiously.

Larger effusions were seen occasionally, but the accompanying shortness of breath usually leads to referral to a clinic rather than to discovery in a routine examination. Resolution of the fluid is usually uncomplicated in the non-maligmant cases, but subsequent radiographs are likely to show evidence of pleural thickening, which may be of either the limited or the extensive type.

Extension of the pleural thickening upwards towards the lung apex was seen in a small number of cases, and it would seem that only the limitations of standard radiographic techniques prevented more frequent demonstration of this reaction on all aspects of the pleural surfaces.

Additional linear shadows, especially in the lower zones, are often seen in conjunction with extensive pleural thickening, and deformity or displacement of the lesser fissure is common. These shadows seem likely to represent changes in the visceral pleura, but with progressive involvement the normal pulmonary pattern is increasingly obscured, and it becomes unprofitable to attempt to discriminate between pleural and pulmonary changes on radiographic evidence alone.

Cases in which the radiographic features of pulmonary fibrosis predominate formed a small but clearly recognizable group. Pleural changes were rarely absent in this group, but, provided these did not obscure the lung fields, the characteristic nodular and linear opacities could be satisfactorily demonstrated (Fig. 4, Special Plate).

\section{Classification}

Definition in purely radiographic terms is practicable for the limited pleural plaque, but in all other cases additional diagnostic criteria are needed in order to differentiate those in which the fibrotic reaction involves the parenchyma of the lungs. A preliminary requirement in all cases was adequate evidence of exposure to asbestos. The diagnosis of pulmonary fibrosis was accepted only when the typical persistent basal rales were detected and when reduction in the gas transfer factor to less than $70 \%$ of the predicted value was confirmed (CO single breath technique). Cases in which any other cause of pulmonary fibrosis was suspected have been excluded.

The term "pleural plaque" has been restricted to those cases in which the extent of the pleural thickening did not exceed the equivalent of four rib interspaces on either side and in which the degree of pleural thickening was insufficient to obscure the normal pulmonary vascular pattern.

Cases of more extensive pleural thickening in which a diagnosis of pulmonary fibrosis was not established were placed in an intermediate category. This category inevitably includes borderline cases at both upper and lower limits, and in particular it includes cases in which there were good reasons for suspecting pulmonary fibrosis but in which all the diagnostic criteria were not satisfied. This problem is inherent in any attempt to classify what is in reality a continuous range in the extent of the reaction to a fibrogenic dust.

Cases showing opacities of calcific density have been included in the appropriate category according to the extent of the pleural thickening.

\section{Results in the $10 \%$ Sample}

Pulmonary Fibrosis.- There were four cases of pulmonary fibrosis, of which three were found in the small high-risk group of workers. All three had been laggers ; 15 years had elapsed since they started work in the trade, but none had been exposed for more than 20 years. The fourth was a labourer who had been employed for 29 years, in the course of which he had cleared up lagging debris in an aircraft carrier. Exceptionally high dust counts have been recorded during this procedure.

Extensive Pleural Thickening.-Of the 11 cases in this category two occurred in the high-risk group of trades-one in a lagger and the other in a painter. Seven occurred in trades with recognized intermittent exposure-five in group 2 and two 
in group 3. Of the remaining two cases one had worked as a cleaner in the boilermakers' shop, and also, more significantly, clearing up lagging debris in an aircraft carrier. The other had worked in small craft only, but had previously been a naval engine-room rating for 22 years. In nine of the 11 cases the time since first exposure exceeded 30 years. Of the other two one had been a ship fitter for 18 years and the other had been an engine fitter for no more than 12 years but had previously worked as a ship's engineer.

Limited Plaques.-There were 48 cases showing limited plaques of pleural thickening. Their distribution between the occupational groups was similar to that seen in cases with extensive pleural thickening; 10 were in the high-risk group ; 27 were in trades with intermittent exposure (17 in group 2 and 10 in group 3). The remaining 11 were in group 4 . The time since first exposure was over 25 years in 35 of the 48 cases. It was under 15 years in six cases. Two of these were laggers, but one had also worked as a boilermaker for 27 years. Of the other four one had previously spent 31 years maintaining steam turbo-generators in a power station, one had worked as a plumber for 11 years before continuing in the same trade in the dockyard, one was a painter's assistant and had probably been heavily exposed at times, and the fourth is mentioned below as an unusual case of biapical calcification.

Calcification.-Opacities of calcific density were observed in seven cases and occurred in all the occupational groups with recognized exposure. In all but one case the first exposure had been more than 26 years previously, and the average was 33 years. The other case was unusual. Calcification was limited to the extreme apical pleura on both sides symmetrically. The industrial history included 12 years as an electrical fitter in the dockyard, but this work was limited to the maintenance of the telephone exchanges ashore. There was no satisfactory evidence of exposure either to asbestos or to talc in any previous occupation. The cause of the condition remains unexplained, except on the basis of environmental exposure.

The relation between the three types of abnormality and the time since first exposure in all groups of workers is shown in Fig. 5. The number of laggers who have remained in employment for more than 25 years since first exposure is too small to influence the characteristics of the third column in this figure.

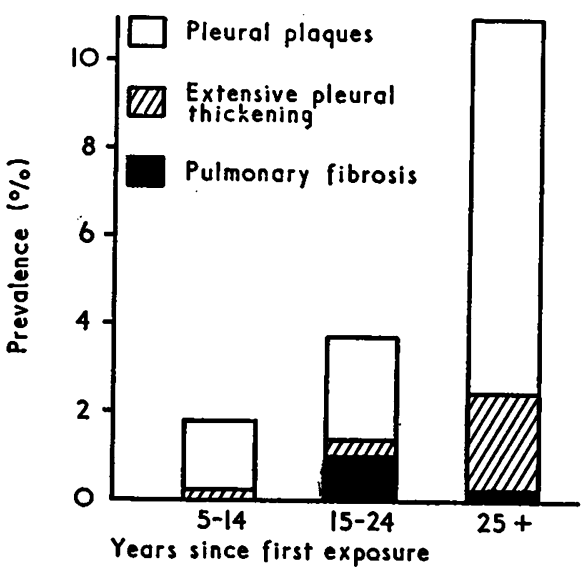

FIG. 5.-Types of abnormality related to time since first exposure (all exposure groups).

\section{Prevalence}

The prevalence of all types of abnormality attributed to asbestos was $4.4 \%$ (63 cases in $1,414 \mathrm{men}$ ). A total of over 600 cases in the dockyard as a whole may therefore be expected. This figure gives an indication of the size of the problem, but because of the wide variation in working conditions further breakdown is necessary before comparisons can be drawn.
Fig. 6 relates the prevalence to the four exposure groups and also shows the distribution of the three types of abnormality. These rates are subject to error on account of the small number of men in group 1 (only $3 \%$ of the total) and are not adjusted for differences in age structure. Analysis shows that the number of men over 45 years of age is a little

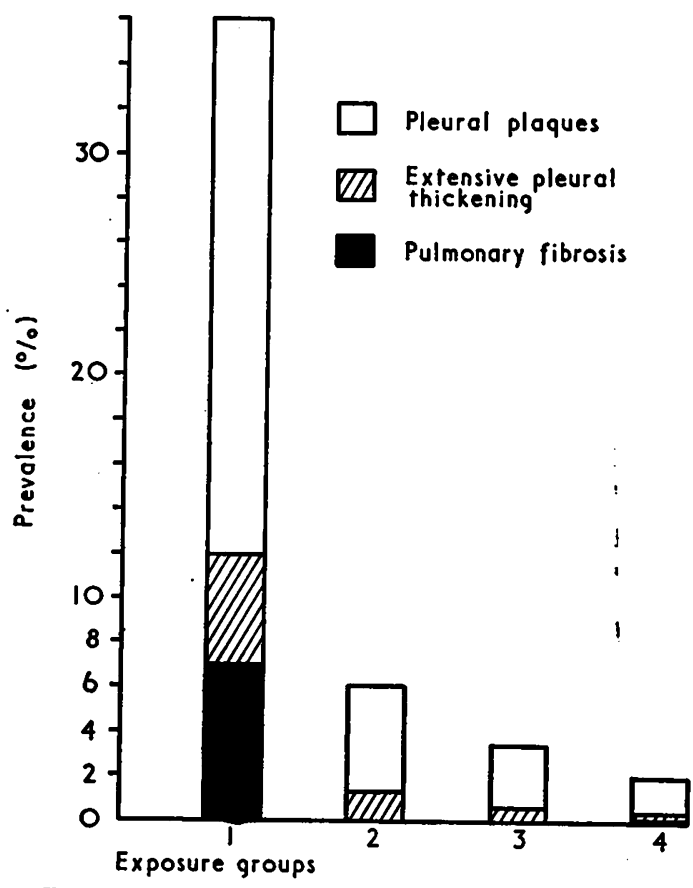

FIG. 6.-Types of abnormality related to exposure groups.

higher than would be expected in group 1 and substantially higher in group 4 . In group 3 the number in this age bracket is lower than would be expected, and the same applies to men aged 55-64 in group 2 (Table IV). This difficulty can be largely overcome by relating the prevalence in each group to the time since first exposure (Fig. 7).

\begin{tabular}{|c|c|c|c|c|c|}
\hline \multirow{2}{*}{ Age } & \multicolumn{4}{|c|}{ Exposure Group } & \multirow{2}{*}{ Total } \\
\hline & 1 & 2 & 3 & 4 & \\
\hline $\begin{array}{l}15-24 \\
25-34 \\
35-44 \\
45-54 \\
55-64 \\
65+ \\
\end{array}$ & $\begin{array}{r}4 \\
9 \\
10 \\
10 \\
9 \\
- \\
\end{array}$ & $\begin{array}{r}117 \\
52 \\
63 \\
74 \\
45 \\
4 \\
\end{array}$ & $\begin{array}{r}94 \\
78 \\
70 \\
46 \\
43 \\
2 \\
\end{array}$ & $\begin{array}{r}105 \\
91 \\
109 \\
189 \\
176 \\
14 \\
\end{array}$ & $\begin{array}{r}320 \\
230 \\
252 \\
319 \\
273 \\
20\end{array}$ \\
\hline Total & 42 & 355 & 333 & 684 & 1,414 \\
\hline
\end{tabular}

The most obvious feature is the much higher prevalence of all types of abnormality in men experiencing continuous occupational exposure (group 1). The number in this group is too small to justify detailed analysis in a $10 \%$ sample, but it is important to note that the majority of cases of pulmonary fibrosis occurred within this group and that in consequence the number of men suffering disabling disease was small in relation to the total number of men in the industry.

On the other hand, though the prevalence of pleural abnormalities in groups 2,3 , and 4 is relatively low, the numbers involved are large and indicate a total of little under 600 cases. The difference between group 2 and group 3 is small and probably of little significance. In both groups a sharp rise in prevalence occurred when the time factor exceeded 25 years. This applied equally to time since starting work and to time spent in the exposed occupation (Table V). The prevalence of pleural abnormalities in these two groups combined after 25 years or more since first exposure was $14 \%$ ( 28 cases in 199 men). 
In group 4 over half the workers experienced little more than environmental exposure, and this is reflected in the prevalence rate of $1.9 \%$.

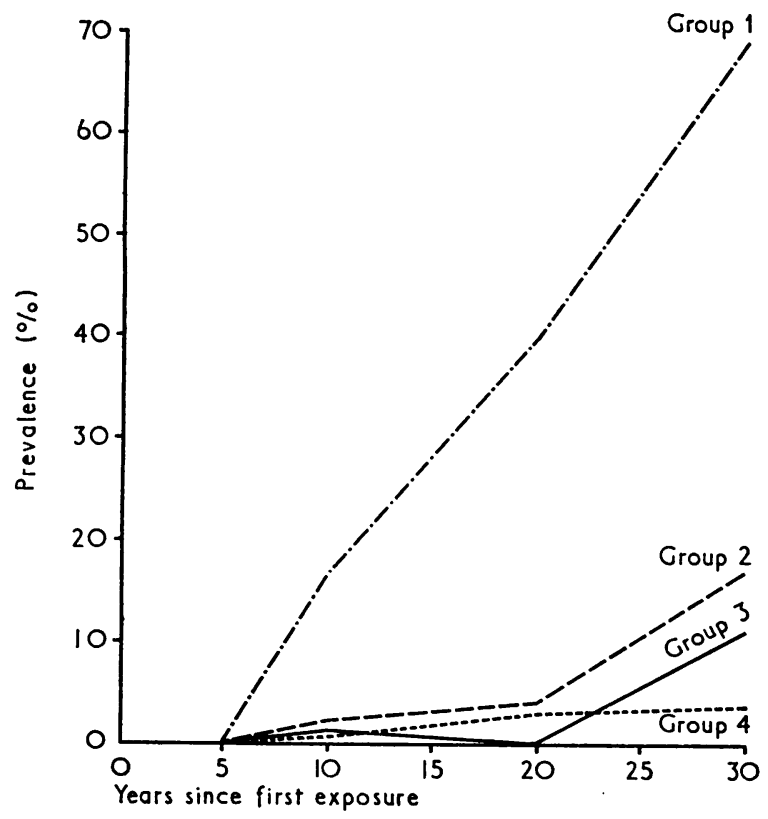

FIG. 7.-Prevalence of abnormalities (all types) in exposure groups related to time since first exposure.

The proportion of pleural abnormalities classified as extensive pleural thickening was a little over one in six. This proportion showed little variation between the four exposure groups but rose to one in four after 25 years had elapsed since first exposure.

\section{Malignant Diseases}

Mesothelioma.-The first histologically confirmed case of mesothelioma of the pleura occurred in 1964 in a man who had been a boilermaker for 31 years. On retrospective review it seems probable that other cases had occurred during the preceding decade. Since 1964 the numbers confirmed were: three in 1965, two in 1966, and five in 1967. One case was found in the 1966 survey (not in the sample) with a small pleural reaction in the left costephrenic angle. In every case there had been intermittent exposure to asbestos of all types in the course of long periods of employment in the dockyard. The time since first exposure exceeded 30 years in all but one. Peritoneal involvement was not observed.

Bronchogenic Carcinoma.-Two cases of bronchogenic carcinoma were found in the sample, and this incidence happens to conform to the average figure of 20 cases expected in one year in dockyard workers under the age of 65 . Insufficient evidence has as yet been accumulated to establish an association between this tumour and the effects of exposure to asbestos in the dockyard.

\section{Other Abnormalities}

Pulmonary Tuberculosis.-One case of sputum-positive tuberculosis was found in the sample. Two others were given prophylactic chemotherapy for small, doubtfully healed lesions. The annual incidence of new cases of pulmonary tuberculosis in dockyard workers has fallen from 15 in 1962 to four in 1967. These rates are lower than those for other men between the ages of 15 and 64 living in the county borough of Plymouth. The rate for Plymouth is the same as the average rate for England and Wales (41 per 100,000 males aged 15 to 64). Care has been taken to exclude tuberculosis as a possible cause of pleural thickening. In cases where any doubt has risen on this point the abnormality has been recorded as postinfective pleural thickening and excluded from those attributed to asbestos. The number in the sample classified in this way was 39. This is more than would be expected, and it is reasonable to suspect that in some cases asbestos may have been a factor. Pleural effusions presented a similar problem in differential diagnosis, but none occurred in the $10 \%$ sample.

Other Conditions.-Of the conditions stimulating diffuse pulmonary fibrosis, only two were identified within the $10 \%$ sample. One was a case of sarcoidosis in which subsequent observation has shown partial resolution of the diffuse pulmonary nodulation. The other was a previously diagnosed case of complicated coal miner's pneumoconiosis. The prevalence of bronchitis and emphysema is fortunately low in Plymouth, and in very few cases has airway obstruction interfered with clinical and functional assessment.

\section{Discussion}

The occupational structure and pattern of exposure to asbestos in the dockyard leads to the risk of the development of pleural abnormalities in a disproportionately large number of men. The prevalence and possible complications of these conditions are therefore of particular importance.

The prevalence rates cover a wide range, corresponding to the variety of working conditions in so heterogeneous a labour force. At one end of the scale, on the basis of the $10 \%$ sample, the expected prevalence of pleural abnormalities among the 420 continuously exposed men $(28 \%)$ is comparable with the rate of $24 \%$ observed in New York insulation workers (Selikoff, 1965). At the lower end of the range there are over 6,800 men with little exposure among whom the prevalence rate is $1.9 \%$. In an environmentally exposed community living near the anthophyllite mines in Finland the highest rate was slightly below $1 \%$ (Kiviluoto, 1960). Occupying an intermediate position there is the important group of approximately 2,000 skilled tradesmen with over 25 years of intermittent exposure and a prevalence rate of $14 \%$. Half the total of pleural abnormalities occur in this group, and these include 70 of the expected 110 cases of extensive pleural thickening.

Necropsy studies suggest that only $15 \%$ of all pleural plaques can be detected radiographically, and that these are those most densely calcified (Hourihane, Lessof, and Richardson, 1966). In recent reports an increasing number of less dense pleural

TABLE V.-Prevalence Related to Time Since First Exposure and to the Time Spent in Exposed work

\begin{tabular}{|c|c|c|c|c|c|c|c|c|c|c|c|c|c|c|c|c|c|c|c|c|c|}
\hline \multirow{2}{*}{\multicolumn{4}{|c|}{ Group }} & \multicolumn{8}{|c|}{ Years Since First Exposure } & \multicolumn{8}{|c|}{ Years Spent in Exposed Work } & \multirow{2}{*}{\multicolumn{2}{|c|}{ Total }} \\
\hline & & & & \multicolumn{2}{|c|}{$0-4$} & \multicolumn{2}{|c|}{$5-14$} & \multicolumn{2}{|c|}{$15-24$} & \multicolumn{2}{|c|}{$25+$} & \multicolumn{2}{|c|}{$0-4$} & \multicolumn{2}{|c|}{$5-14$} & \multicolumn{2}{|c|}{$15-24$} & \multicolumn{2}{|c|}{$25+$} & & \\
\hline 1 & $\left\{\begin{array}{l}\text { No. examined } \\
\text { No. abnormal }\end{array}\right.$ & $\because$. & $\because$. & 7 & - & 12 & 2 & 10 & 4 & 13 & 9 & 10 & 2 & 15 & 4 & 11 & 4 & 6 & 5 & 42 & 15 \\
\hline 2 & $\left\{\begin{array}{l}\text { No. examined } \\
\text { No. abnormal }\end{array}\right.$ & $\because$ & $\because$ & 85 & - & 95 & 2 & 75 & 3 & 100 & 17 & 85 & - & 110 & 4 & 77 & 3 & 83 & 15 & 355 & 22 \\
\hline 3 & $\left\{\begin{array}{l}\text { No. examined } \\
\text { No. abnormal }\end{array}\right.$ & .. & $\therefore$ & 76 & - & 83 & 1 & 75 & - & 99 & 11 & 76 & - & 98 & 1 & 71 & - & 83 & 11 & 333 & 12 \\
\hline 4 & $\left\{\begin{array}{l}\text { No. examined } \\
\text { No. abnormal }\end{array}\right.$ & $\because$ & $\because$ & 159 & - & 196 & 2 & 135 & 4 & 194 & 8 & 163 & - & 212 & 4 & 153 & 4 & 156 & 6 & 681 & 14 \\
\hline Total & $\left\{\begin{array}{l}\text { No. examined } \\
\text { No. abnormal }\end{array}\right.$ &.. & $\therefore$ & 327 & - & 386 & 7 & 295 & 11 & 406 & 45 & 334 & 2 & 435 & 13 & 312 & 11 & 333 & 37 & 1,414 & 63 \\
\hline
\end{tabular}


opacities have been described (Anton, 1967 ; Leathart, 1967), but it seems evident that a large proportion of pleural abnormalities remain undiscovered and that prevalence rates based on radiographic surveys are considerably underestimated.

Pulmonary fibrosis occurred in a variety of trades in which exposure was intermittent, and appeared to be a definite risk in some cases of extensive pleural thickening. In 50 such cases seen locally during the last five years an attempt was made to apply the distinction drawn by Elmes (1966) between circumscribed hyaline fibrosis in the parietal pleura and a diffuse pleural thickening with ill-defined margins, most pronounced over the lower lobes, which he relates to underlying parenchymal disease. There was considerable overlap between the two varieties in some of our cases, but it would be reasonable to regard 26 as parietal pleural thickening and 24 as mainly diffuse lower-zone fibrosis. All five cases in which a diagnosis of pulmonary fibrosis was subsequently established occurred among the 24 with diffuse lower-zone fibrosis.

A possible explanation for the predominance of pleural over parenchymal changes is that the intermittent exposure experienced in most of these cases has allowed sufficient time to elapse for the appearance of pleural reactions, while the dust concentrations were insufficient to give rise to pulmonary fibrosis as the presenting feature.

A further cause of anxiety is the possibility of a relation between pleural fibrosis and malignancy. Our first case of mesothelioma was preceded by extensive parietal pleural thickening for more than five years. Others have developed in the neighbourhood of previously identified limited pleural plaques. In addition to those with recognized pleural fibrosis there are at present in the dockyard over 1,200 men whose first occupational exposure to asbestos was more than 30 years ago, and a further 1,000 who have been environmentally exposed for a similar period. The large number of retired men living in the district must be added to these in order to gain an impression of the number who may be at risk.

It is hoped that the long-term study of a series of all types of pleural thickening will help to assess the added risks of malignancy and morbidity from extending fibrosis.

We would like to thank Surgeon-Commander P. G. Harries, Royal Navy, for his close collaboration and for help with pulmonary function studies ; Dr. J. C. Gilson for encouragement and valued advice; the Admiral Superintendent of the Dockyard and his staff for their co-operation; and the staff of the Mass Radiography Service for their skilled work. The investigation was supported by a research grant from the South-western Regional Hospital Board.

\section{REFERENCES}

Anton, H. C. (1967). Brit. f. Radiol., 40, 685.

Elmes, P. C. (1966). Postgrad. med. 3 ., 42, 623.

Harries, P. G. (1968). Ann. occup. Hyg., 11, 135.

Hourihane, D. O'B. Lessof, L., and Richardson, P. C. (1966). Brit. med. F., 1, 1069.

Kiviluoto, R. (1960). Acta Radiol. (Stockh.), Suppl. No. 194.

Leathart, G. L. (1967). Unpublished.

Selikoff, I. J. (1965). Ann. N.Y. Acad. Sci., 132, 351.

\title{
Chloroquine: Ophthalmological Safety, and Clinical Assessment in Rheumatoid Arthritis
}

\author{
S. P.'B. PERCIVAL,* M.A., M.B., D.o. ; I. MEANOCK, $†$ M.D., M.R.C.P.
}

Brit. med. F., 1968, 3, 579-584

\begin{abstract}
Cummary : 272 patients on long-term chloroquine therapy were assessed with respect to ocular toxicity and clinical benefit. A simple scheme for rendering patients ophthalmologically safe is presented, employing the recording of central fields to red targets. Under this it was possible to diagnose a state of premaculopathy, which was reversible on stopping treatment. The incidence of premaculopathy was $41 \%$ in 143 patients who otherwise displayed no abnormality of the fundus oculi and who had received a mean total dose of $410 \mathrm{~g}$. of chloroquine phosphate or the hydroxychloroquine sulphate equivalent. Under this joint ophthalmological and rheumatological supervision it was considered that the minor side-effects that may be caused by chloroquine are outweighed by its therapeutic value.
\end{abstract}

\section{Introduction}

In spite of undoubted therapeutic value in centain disorders, the use of the antimalarials chloroquine phosphate (Avlochlor), hydroxychloroquine sulphate (Plaquenil), and chloroquine sulphate (Nivaquine) has been losing favour in clinical practice

\footnotetext{
* Ophthalmic Registrar, Royol Berkshire Hospital, Reading. Present address: The Eye, Ear, ond Throat Hospital, Shrewsbury.

+ Consultant Physician in charge of Rheumatic Diseases and Physical Medicine Departments, Reading and District Hospitals Group.
}

because of ocular toxicity. It is the purpose of this paper to show how antimalarials may be rendered ophthalmologically safe and to assess the clinical and functional status of a group of patients on continuous antimalarial therapy, the majority of whom had rheumatoid disease.

\section{Material and Methods}

The 272 outpatients taking part in the survey were referred from the departments of rheumatology and dermatology to the ophthalmic outpatient department during 1964 and the early part of 1965 . Their age and sex are shown in Table $I$.

TABLB I.-Age and Sex

\begin{tabular}{c|c|c|c|c|c|c|c|c}
\hline \multirow{3}{*}{ Patients } & \multicolumn{3}{|c|}{ Male Aged } & \multicolumn{3}{|c|}{ Female Aged } & \multirow{2}{*}{ Total } \\
& $20-40$ & $41-60$ & $61-80$ & $20-40$ & $41-60$ & $61-85$ & \\
\hline \begin{tabular}{l|c|c|c|c|c|c} 
Rheumatoid \\
Skin
\end{tabular} & 8 & 36 & 25 & 28 & 118 & 37 & 253 \\
\hline
\end{tabular}

The standard daily dose of antimalarial was $250 \mathrm{mg}$. of chloroquine phosphate or $200 \mathrm{mg}$. of hydroxychloroquine sulphate. Five patients had also received courses of chloroquine sulphate. Ninetythree received double the daily dose during the first part of their course, and 43 received half the daily dose during the course when control at this level seemed satisfactory. 